\title{
Express Biosensor control of maize plants under different agrotechnical procedures
}

\author{
R. Son'ko ${ }^{1}$, O. Marchenko ${ }^{1}$, V. Kolomijez' ${ }^{2}$, N. Starodub ${ }^{1}$ \\ ${ }^{1}$ National University of Life and Environmental Sciences, \\ Heroyiv Oborony st., 15, Kyiv-03041, Ukraine \\ nikstarodub@yahoo.com \\ ${ }^{2}$ National Scientific Centre "Institute of Agriculture“, \\ Mashynobudivnykiv str., 2 B, Township Chabany, Kyevo-Svyatoshynskyi district Kyiv region, 08162
} Ukraine

\begin{abstract}
:
It was used the developed portable optical biosensor „Floratest" for the express control of state of the maiz plants at the different agrotechnical procedures. The induction of fluorescence of chlorophyl was served as the main registered index. It was revealed the differences in the photosynthetic activities of plants in depending on soil preparation and nutrition by the fertilizer outside of root system.
\end{abstract}

Key words: portable optical biosensor „Floratest“, agrotechnical procedures, maiz state, express control.

\begin{abstract}
Introduction
The development of the reliable methods for express evaluation of the functional condition of crops during their growing season is very important direction of modern plant physiology. In this case, the state of the photosynthetic apparatus is one of the most important indicators that directly affect on the quality and quantity of the final harvest. Using chlorophyll fluorescence induction provides an opportunity to explore and analyze the efficiency of photochemical reactions in photo system 2, which is considered as the most sensitive to environmental factors [1]. Today this method is one of the most promising and available for use by the agricultural area.
\end{abstract}

Induction of chlorophyll fluorescence (IChF) was firstly investigated by Kautsky, so this effect has his name. During induction of chlorophyll fluorescence the generated signal at first increases and then decreases. The dependence of IChF from time to time after the light action is known as induction curve [1]. Influence of stressors on IChF described in many studies. In particular, it is given the data about changes of the calculated indices fluorescence at different levels of water deficit in pea plants [4], sunflower and maize [6] and the effect of nitrogen nutrition conditions in water stress [7], with varying root and root out power [3] and other cases. It was found too the correlation between the influence of biotic factors on plant corn and changing rate of activity photo system 2 (PhS-II) [5]. As a result of these studies it was stated that its activity was different in respect of the sensitivity and resistivity to disease depends on genotypes.

Early it was developed portable biosensor named as "Floratest" [2] and now the main aims of this report is the demonstration of the efficiency of this device at its application at the control of maize plants state under different agro technical procedures.

The developed device is constructed as an open system, a variable optical remote sensors and original methodological support that enable to quickly target it to a particular application. Its application provides the user with the following features: express evaluate vital functions of plants after drought, cold, traction, making pesticides; rapid determination of optimal doses of organic and mineral fertilizers and biological additives to optimize fertilizer use and biological additives and to reduce the nitrate content in vegetables; optimize technology precision farming; express determine water contamination, soil and air with pesticides, heavy metals and industrial emissions, save energy and water resources in artificial irrigation; predict results for future crops, such as agriculture insurance, provide automation research in plant physiology. 


\section{Experimental}

The experiments was curried out research on crops of National Scientific Centre „Institute of Agriculture" with the preliminary characterized soils and in semypilniy grain-tilled crop rotation in field corn. Nitrogen fertilizer brought under cultivation presowing. Also, at a phase 5, 7 and 10 leaves it was used compound fertilizers foliar feed that contained the basic elements $(N, P$, $\mathrm{K})$ and trace elements (As, $\mathrm{Cu}, \mathrm{Fe}, \mathrm{Mn}, \mathrm{Mo}, \mathrm{Zn}$ ) in chelate forms.

In the course of work it was determined status as fast and slow stages of chlorophyll fluorescence in the time mode for 3 minutes. Dark adaptation of leaves lasted no less than 3minutes, according to recommendations of the device developers.

To characterize the photosynthetic apparatus of plants with IChF curve, resulting from research (Fig. 1) were taken following indicators [1]: Fo the level of fluorescence emitted by photosystem 2 complexes with open reaction centers, where $\mathrm{Qa}$ is in the oxidized state; Fm - chlorophyll fluorescence with closed reaction centers when all Qa restored and can no longer accept electrons; Fpl - fluorescence level when achieving intermediate "plateau" depends on the quantity $\mathrm{Qb}$ - irreplaceable complexes of PhS-II; Fst - chlorophyll fluorescence yield at stationary level.

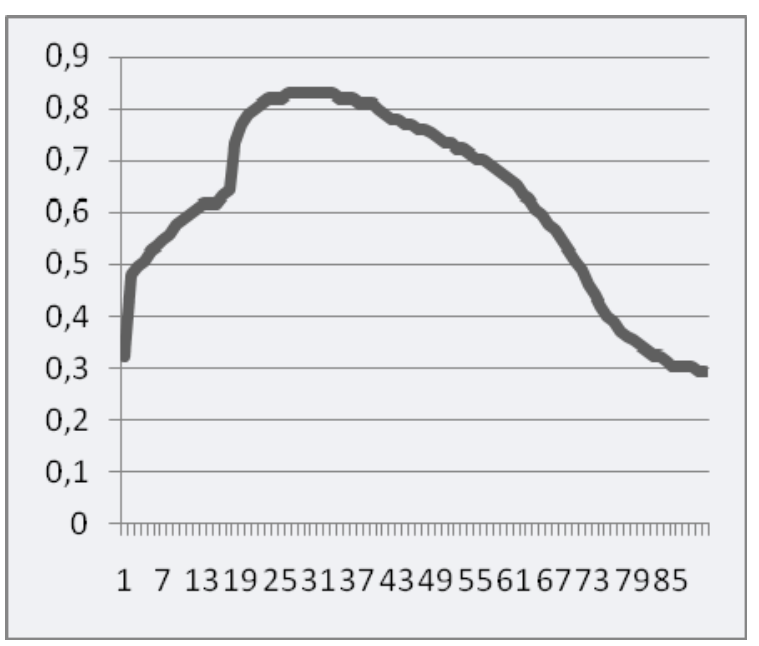

Fig. 1 Typical IChF curve of maize.

Based on the results, calculated as the following parameters: Fv, which characterizes the activity elektrontransportnoho chain (ETL); Fv/Fo, as an indicator of photochemical activity photosystems II; (Fpl-Fo)/Fv, indicating the increase in $\mathrm{Qb}$ (non-renewable systems PhS II, which do not participate in linear electron transport, leading to a reduction of primary products of photosynthesis); Fm/Fst, indicating the effectiveness dark stage of photosynthesis and Fv/Fm, which corresponds to the total number of active complexes of PhS-II.

\section{Results and discussion}

It was stated (Tab. 1) that fertilizer leaf of maize during the growing season causes increased pressure on photosystem, activating additional ways for electronic outflow and increasing the synthesis of chlorophyll, along with increased consumption of ATP molecules, which leads to a decrease in fluorescence quenching by non photochemical way [1].

Tab: 1. Influence of foliar feeding of plants. corn on performance IFH.

\begin{tabular}{|l|c|c|}
\hline \multirow{2}{*}{ Indexes } & \multicolumn{2}{|c|}{ Variantle of experiment } \\
\cline { 2 - 3 } & $\begin{array}{c}\text { fertilizer leaf } \\
\text { of maize }\end{array}$ & Control \\
\hline Fv & $0,38 \pm 0,07$ & $0,43 \pm 0,06$ \\
\hline Fv/Fo & $0,89 \pm 0,14$ & $1,20 \pm 0,26$ \\
\hline (Fpl-Fo)/Fv & $0,42 \pm 0,09$ & $0,49 \pm 0,10$ \\
\hline Fm/Fst & $2,63 \pm 0,18$ & $2,65 \pm 0,17$ \\
\hline Fv/Fm & $0,47 \pm 0,04$ & $0,54 \pm 0,06$ \\
\hline
\end{tabular}

In the plants treated by out root fertilizing the intensity of fluorescence was increased (Fig. 2). First phase IChF was most sensitive to fertilizer, to be exact rate that characterizes the fluorescence emission complexes PS II with open reaction centers (F0). Such indexes as $\mathrm{Fm}, \mathrm{Fpl}$ and Fst, while indicating at increasing intensity chlorophyll fluorescence but these values are low and fluctuate within $2-3 \%$.

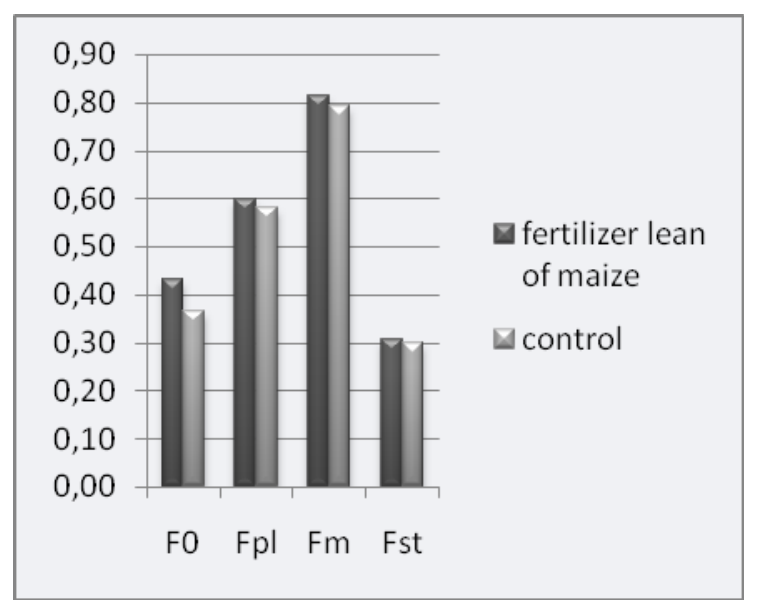

Fig. 2. Dependence of photo luminescent indexes on treatment of plats by leaf fertilizer

The results indicate on the increasing $Q b$ - nonrenewable systems, if the fertilizer was absent. This increase in $\mathrm{Qb}$ may indicate significant damage acceptor PhS-II in plants. In case of using feeding the efficiency ETL, PhS-II and 
the quantum yield of photochemical reactions decreased. Thus, foliar fertilization of corn during the growing season causes increased pressure on photo systems, activation of additional ways electronic brain and increasing the synthesis of chlorophyll, along with increased consumption of ATP molecules, which leads to a decrease in photochemical quenching of fluorescence is $[1,3]$.

It should be noted that the application of plowing increased the relative content of $\mathrm{Qb}$ non recovery complexes PhS-II. This may indicate a slight increase in the intensity of damage to the acceptor side of PhS-II. Bringing data can be explained to stimulate the process of photosynthesis, causing increasing adaptability of primary processes of photosynthesis in plants in form with the use of plowing, while the version with subsurface tillage observed some violations complexes FSII (Tab. 2).

Tab: 2. Influence of different methods of basic surface tillage on indexes of IPHS

\begin{tabular}{|l|c|c|}
\hline \multirow{2}{*}{ Indexes } & \multicolumn{2}{|c|}{ Option tillage } \\
\cline { 2 - 3 } & ploughing & $\begin{array}{c}\text { subsurface } \\
\text { tillage }\end{array}$ \\
\hline Fv & $0,42 \pm 0,05$ & $0,36 \pm 0,08$ \\
\hline Fv/Fo & $1,06 \pm 0,24$ & $0,86 \pm 0,16$ \\
\hline (Fpl-Fo)/Fv & $0,48 \pm 0,08$ & $0,37 \pm 0,08$ \\
\hline Fm/Fst & $2,64 \pm 0,13$ & $2,63 \pm 0,25$ \\
\hline Fv/Fm & $0,51 \pm 0,05$ & $0,46 \pm 0,05$ \\
\hline
\end{tabular}

Fig. 3 shows the dependence of fluorescence parameters derived from plants, depending on various options for tillage. Plants were grown in soil with subsurface tillage, performance intensity of IPhF have lower values. The level of fluorescence in the period to achieve an intermediate plateau shows the greatest difference in fluorescence intensity at $10 \%$. However, the $F_{0}$ value unlike other values indicates on a greater intensity of fluorescence in plants with ploughing.

Analysis of the results (Tabl. 2) shows that the maximums of the photochemical efficiency and values of indexes of PhS-II (Fv / Fm) are differed for the two versions of soil treatment. Thus, in the variant of ploughing these values were higher than the values at the subsurface tillage. In the variant of ploughing indicator of photochemical activity PhS-II (Fv / Fo) was also significantly higher. Moreover, in the first type of soil treatment (ploughing) it was observed increased rate variable fluorescence (Fv), indicating activation electron transporting chain and more efficient light phase of photosynthesis. However, the performance dark phase of photosynthesis (Fm/Fst) was not significantly differ between the experimental variations, reaching in both cases, of the experiment almost similar values.

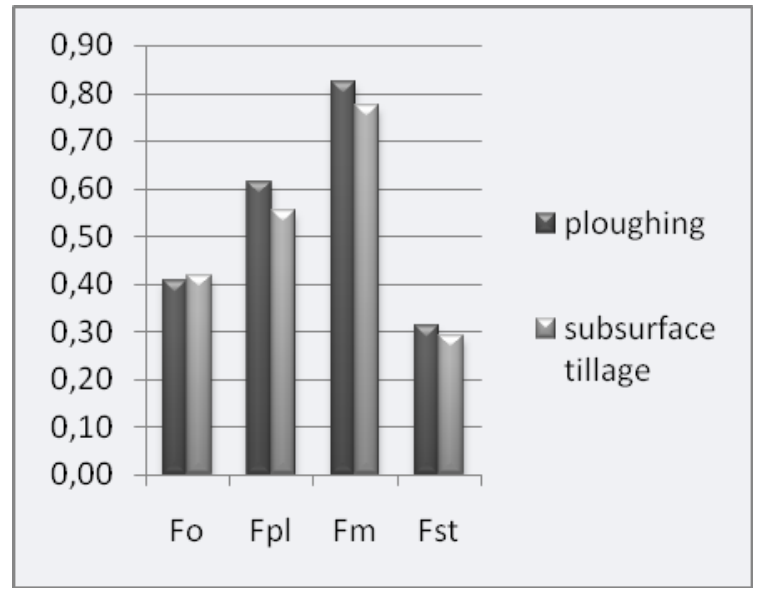

Fig. 3. Dependence of indexes of fluorescence on type of soil treatment.

The intensity of photosynthesis largely depends on the circle of placement of leaves on the plant, age and influence on them during the formation of physiologically active substances. (Fig. 4; Tab. 3). The leaves placed on the lower circles have less performance PSII, more Qb non-renewable systems and greater fluorescence output upon reaching a stationary level. Slightly better indexes are characterized foliate cover of the upper circle in which they occur in 3-5\% better compared with the lower circle. Middle circle of sheet cover of maize has the lowest indexes of IPhF, which is associated with optimal conditions in which there is photosynthetic apparatus.

At the same time, data are given in Table 3 show that with increasing leaf stage of maize, it is observed the decreasing quantum yield of photochemical reactions and photochemical activity of photosystem 2 . This is possible due to the fact that as a result of the last fertilizer spray of leaves lower circle got aggregated triple, medium - a double and top - single rate of trace elements. Thus, in the leaves of the upper circle happening increase in Qb - irreplaceable PS complexes 2, which was manifested in inhibition of reparatory processes and systems damaged acceptor of PS 2. The effectiveness dark stage of photosynthesis increased with increasing quantity of circles (Fm/Fst). Thus, deficiency of trace elements in plants during the formation of leaves may cause systems FSII, which in turn reduces the activity of photosynthetic processes, this process is called photo inhibition [1]. 


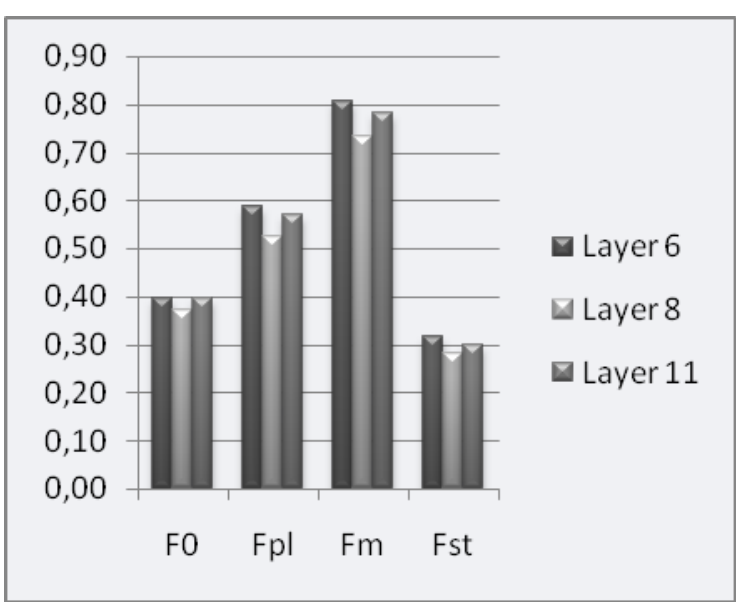

Fig. 4. Dependence of fluorescent indexes on circles of location of maize leaves.

This decrease can be caused by the reverse and regulatory mechanisms that prevent the flow of excitation energy to reaction centers by increasing the heat dissipation, and not the reverse processes (light-induced inactivation of complex PS II). Taken into attention that maize belong to the C4-type plants revealed photo inhibition possible has inverse character and is caused by active adaptation processes.

Tab: 3. Dependence of IChF of maize leaves on location of circles.

\begin{tabular}{|l|c|c|c|}
\hline \multirow{2}{*}{ Indexes } & \multicolumn{3}{|c|}{ Circle of leaves } \\
\cline { 2 - 4 } & 6 & 8 & 11 \\
\hline $\mathrm{Fv}$ & $0,41 \pm 0,02$ & $0,36 \pm 0,09$ & $0,42 \pm 0,06$ \\
\hline Fv/Fo & $1,03 \pm 0,05$ & $0,98 \pm 0,28$ & $0,96 \pm 0,29$ \\
\hline $\begin{array}{l}\text { (Fpl- } \\
\text { Fo)/Fv }\end{array}$ & $0,46 \pm 0,05$ & $0,39 \pm 0,13$ & $0,48 \pm 0,07$ \\
\hline Fm/Fst & $2,54 \pm 0,08$ & $2,57 \pm 0,18$ & $2,8 \pm 0,13$ \\
\hline Fv/Fm & $0,5 \pm 0,011$ & $0,49 \pm 0,07$ & $0,48 \pm 0,07$ \\
\hline
\end{tabular}

\section{Conclusion}

With help of the developed biosensor it was stated that the fertilizer leaf of maize during the growing season may cause increased pressure on photosystems, activating additional by electronic outflow.
Application plowing stimulates the processes of photosynthesis, causing increasing adaptability of primary processes of photosynthesis.

And it was mentioned that with increasing circle of location of leaves of maize, a decrease in photochemical activity of PSII and the quantum yield of photochemistry. This phenomenon is reversible and is determined by the active processes of adaptation to fertilizer.

\section{References}

[1] D.Ju. Korneev, Informational possibility of methods of induction of chlorophyll fluorescence, K., Al'tpress, (2002) 188p.

[2] N.F. Starodub, R.V.Son'ko, V.O. Romanov, I.P. Galelyuka In Book: "The SENSOR+TEST 2011", AMA Service GmBH, Nurenberg, 133-138 (2011).

[3] Bajrak N.V., Zuza V.A., Pogromskaja Ja.A. Application of method of chlorophyll fluorescence induction for studying inhomogeneities system of plant photosynthesis. Herald of V.N. Karazin Charkiv University. Ser.: Biology N 814, 181-186, (2008).

[4] Posudin Ju.I., Bohdasheva O.V. Fluorescent analysis of pea seeds Pisum sativum during development and at the influence of external factors. Scientific Proceedings NUBiP. 2010-5 (21).http://www.nbuv.gov.ua/e-journals/Nd/ 2010 5/ 10pyieef.pdf

[5] Duraes F. O. M. The usefulness of chlorophyll fluorescence in screening for disease resistance, water stress tolerance, aluminum toxicity tolerance, and $\mathrm{n}$ use efficiency in maize / F. O. M. Duraes, E. E. G. Gama, P. C. Magalhaes [et al.] // Seventh Eastern and Southern Africa Regional Maize Conference $11^{\text {th }}-15^{\text {th }}$ February 2001, pp.356-360

[6] Yordanov I., Tsonev T., Goltsev V. [et al.] Interactive effect of water deficit and high temperature on photosynthesis of sunflower and maize plants 1. Changes in parameters of chlorophyll fluorescence induction kinetics and fluorescence quenching. Photosynthetica, 33(34), 391-402 (1997)

[7] Shangguan Z., Shao M., Dyckmans J. Effects of nitrogen nutrition and water deficit on net photosynthetic rate and chlorophyll fluorescence in winter wheat. J. of Plant Physiology, 56(1), 4651 (2000). 